\title{
Hydrolytic enzyme production of endophytic fungi isolated from soybean (Glycine max)
}

\author{
Hala Montaser Farouk ${ }^{1}$, Eman Zekry Attia ${ }^{2^{*}}$, Mo'men H. El-Katatny ${ }^{1}$ \\ ${ }^{1}$ Department of Botany and Microbiology, Faculty of Science, Minia University, 61519 Minia, Egypt \\ ${ }^{2}$ Department of Pharmacognosy, Faculty of Pharmacy, Minia University, 61519 Minia, Egypt \\ * Correspondence: eman_zekry@mu.edu.eg; Tel: +20 862369075; Fax: +20 862347767
}

\section{Article information \\ Received: 6 Augest 2019 \\ Revised: 27 Augest 2019 \\ Key words \\ Fungal endophytes \\ Hydrolytic enzymes \\ Growth stimulation \\ Growth inhibition \\ Soybean}

Accepted: 28 Augest 2019

\begin{abstract}
This current approach aimed to isolate endophytic fungi from the roots, stems and leaves of soybean (Glycine max L.) and to assess for their ability to produce hydrolytic extracellular enzymes such as carboxymethyl cellulase (CMC-ase), xylanase and amylase in order to evaluate their ecological role within the host plant. Ten endophytic fungi were isolated from soybean (roots, stems, and leaves). All isolated endophytes (100\%) exhibited CMC-ase, xylanase and amylase activities using the minimal synthetic medium (MSM) for enzyme production supplemented with $2 \%$ agar in the presence of the appropriate carbon source including carboxymethyl cellulose (CMC) for CMC-ase, xylan for xylanase and starch for amylase. They were differentiated into 5 different genera, including Aspergillus, Fusarium, Nigrospora,Trichoderma and Dark sterile mycelia. All the endophytic isolates showed growth stimulation on CMC and xylan media, and were hyperactive in the presences of these substrates more than glucose. On the other hand, starch was investigated as lower preferable substrate for these endophytes. These relevant results endeavored to explore endophytic fungi and to investigate their production of industrial microbial enzymes.
\end{abstract}

\section{Introduction}

In the past, microbes including bacteria and fungi that live inside the plants without producing any damage to their host plant during their life cycle, were called endophytes but recently, protists, archaea, fungi and bacteria that inhabit in plants were called endophytes, regardless the outcomes of this correlation [1,2]. Considerable benefits of endophytes to the host plant have been reported. They can enhance the growth of host plants, improve the resistance to abiotic and biotic stresses [2] and produce bioactive secondary metabolites [3]. In view of the fact that, the endophytes can be detected in almost all species of living plants, a systematic base in plant assortment is essential for the study of endophytes to isolate microorganisms with pharmaceutical prospect $[4,5]$.

The correlation among the endophytes and their host plants may extend from dormant phytopathogenesis to mutualistic symbiosis. Endophytic fungi could produce extracellular hydrolytic enzymes as other organisms infesting plant tissues, in order to resist any pathogenic invasions as well as to acquire the essential nutrition from their host, such as cellulases, xylanses and amylases [6]. Such enzymes displayed variable important applications in industry, like the production of biofuel, detergents, food and pharmaceutical products [7].

The soybean (Glycine $\max$ L.) is one of the most widely grown leguminous crops worldwide due to the high oil and protein content of its grain. It is usually used in human and animal nutrition and in the production of biodiesel, disinfectants, lubricants, soap, and cosmetics [8]. It represents a major source of high quality protein; low content in saturated fat and a great amount of dietary fiber. It is worth mentioning that its isoflavone content makes it remarkable among other legumes [9].

Up to date, there are few reported studies on the endophytic fungi associated with soybean. The objective of this study was to isolate and identify the endophytic fungi from the roots, stems and leaves of soybean as well as to determine their potential in production of some important hydrolytic enzymes.

\section{Materials and methods}

\subsection{Chemicals and Collection of plant material}

The used chemicals and reagents in this study were obtained from Sigma-Aldrich, Germany. All chemicals and reagents were of the analytical grade. Fresh mature leaves stems and roots of soybean (Glycine max L.) were collected from a healthy plant grown in the Farm and Botanic Garden of Botany and Microbiology Department, Faculty of Science, Minia University, Minia, Egypt. The fresh samples were taken to the laboratory and treated within $8 \mathrm{hr}$.

\subsection{Isolation and identification of endophytes}

Isolation of endophytic fungi from soybean was carried out using the protocol described by Strobel and Daisy [10] with 
slight modifications. Fresh plant materials (roots, stems and leaves) were collected, washed under running tap water for 10 min and disinfected in series with $70 \%$ ethanol for $1 \mathrm{~min}, 1.0 \%$ sodium hypochlorite $(\mathrm{NaOCl})(\mathrm{v} / \mathrm{v})$ for $1 \mathrm{~min}$ and further cleaned by passing through two sets of sterile distilled water. After surface disinfection, leaves and branches were cut into small pieces $0.5 \mathrm{~cm}$ long. The disinfected samples were placed on a plate containing water agar and potato dextrose agar (PDA) media containing $250 \mu \mathrm{g} / \mathrm{mL}$ streptomycin, which is to suppress bacterial contamination. In addition, aliquots of the final rinse water of the root, stem and leaf fragments were also plated onto PDA as a complementary test of surface disinfection. Petri dishes were incubated at $28 \pm 2{ }^{\circ} \mathrm{C}$ till the fungal mycelia started growing on the cut pieces of samples. The plates were checked every day up to ten days after incubation and any fungi present was isolated, purified and then maintained at $4{ }^{\circ} \mathrm{C}$ on PDA slopes for further morphological identification [11, 12]. The endophytic fungi were purified by transferring emerging hyphae to a new PDA slant. The purified fungal isolates of roots, stems and leaves of soybean were codified and identified morphologically in the centre of Mycology, and colony features were based on the observation on PDA under ambient day light conditions. Endophytes were deposited in Microbial Repository of Botany and Microbiology (MRBM) Department, where they were stored at $4{ }^{\circ} \mathrm{C}$.

\subsection{Screening of fungal endophytes for production of extracellular enzymes}

The production of enzyme by fungal endopytes was qualitatively determined by using method of [13] whereas enzyme production was tested on solid agar media (Halo on cup plate assay). Minimal synthetic medium (MSM) was used for enzyme production [14] supplemented with $2 \%$ agar in presence of the appropriate carbon source (Carboxymethyl cellulose for $\mathrm{CMC}$-ase, xylan for xylanase and starch for amylase). Cultivation of the fungal endophytes was done at 28 ${ }^{\circ} \mathrm{C}$ for 3 days in the tested plates. After incubation period, agar plates for testing CMC-ase and xylanase were stained with 0.2 $\%$ of Congo red dye for 15-20 min, and then washed with $1 \mathrm{M}$ $\mathrm{NaCl}$ solution for 15-20 min [15]. Enzymatic halo "degradation halo" [16, 17] was observed as indicator for the presence of enzyme activity evidenced by the enzymes secretion made by fungi through the culture medium. Visualization of enzymatic halo for xylanase activity in presence of xylan was performed with and without Congo red reagent. Amylase activity was assessed by growing fungal endophytes on MSM medium supplemented with $0.2 \%$ soluble starch from potato at $\mathrm{pH} 6$. After incubation for 3 days, the plates were flooded with $1 \%$ iodine in $2 \%$ potassium iodide. Formation of a clear zone surrounding the colony was considered as positive result for amylase production.

Diameter of enzymatic halo was measured for determination of Enzymatic Index (EI) expressed by the relationship between the average diameter of the degradation halo (Colony diameter + clear zone diameter) and the average diameter of the colony growth. It was suggested that the Enzymatic Index for qualitatively measuring of enzyme activity, where, Enzymatic Index = hydrolysis zone/colony diameter (EI $=\varnothing \mathrm{h} / \varnothing \mathrm{c})[17]$

$$
\mathrm{EI}=\frac{\text { diameter of hydrolysis zone }}{\text { diameter of colony }}
$$

\subsection{Effect of substrate on growth stimulation/inhibition}

Growth simulation/inhibition index was computed as the colony diameter on the tested substrate agar/colony diameter on control agar (in presence of glucose) ratio [18]. The index value $<1$, represented substrate inhibited fungal growth, while the index value $>1$, exhibited substrate rendered growth stimulation.

\section{Results}

A total of ten fungal endophytes were isolated from soybean (Glycine max L.). All of these isolates were identified morphologically on the basis of colony, hyphal morphology of the fungal cultures and characteristics of the spores. The endophytic fungi were purified and coded by numbered label and were identified morphologically as Aspergillus terreus (GMEF1), Fusarium oxysporum 3 (GMEF2), Fusarium oxysporum 4 (GMEF3), Aspergillus fumigates (GMEF4), Nigrospora sp. 1 (GMEF5), Nigrospora sp.2 (GMEF6), Trichoderma harzianum (GMEF7), Fusarium. oxysporum 5 (GMEF8), Dark sterile mycelia 1 (GMEF9), Dark sterile mycelia 2 (GMEF10) (Figure 1). Each isolate were subcultured into a PDA agar plates to remove the adherent plant metabolite from the mycelia and stored at $4{ }^{\circ} \mathrm{C}$ for the further studies. All endophytic fungi were deposited in the strain culture collection of MRBM Department, where they were stored at $4{ }^{\circ} \mathrm{C}$.

\subsection{Production of extracellular enzymes}

The results of qualitative estimation of endophytic fungal enzymes (CMC-ase, Xylanase and Amylase) in solid media amended with the appropriate carbon source (CMC, xylan and starch) are represented in (Tables 1, 2 and 3) and (Figures. 2A, $\mathbf{B}$ and $\mathbf{C})$. The evaluation was performed on solid medium by measuring the degradation halo in the presence of specific substrates. Enzymes assays performed on solid media detected extracellular enzymes, produced and released to the media by the mycelium. The clear zone around the fungal colony indicates degradation of the amended substrate due to enzyme activity. The ability of degrading enzyme of the tested endophytes was estimated in terms of degradation halo (Colony diameter + clear zone diameter) and fungus colony rations. Hundred percent of the isolates showed positive activities for CMC-ase, xylanase and amylase activities. Figure 2 represents the qualitative test conducted for some endophytes in $\mathrm{CMC}$, 
Roots

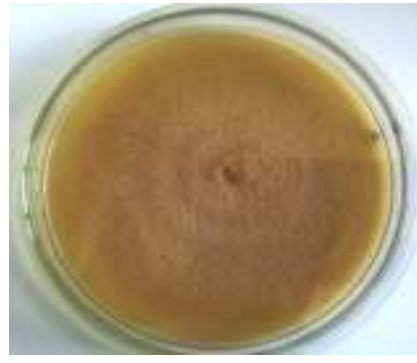

GMEF 1

Stems

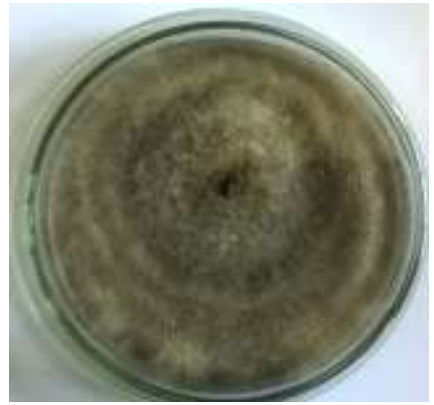

GMEF 5

Leaves

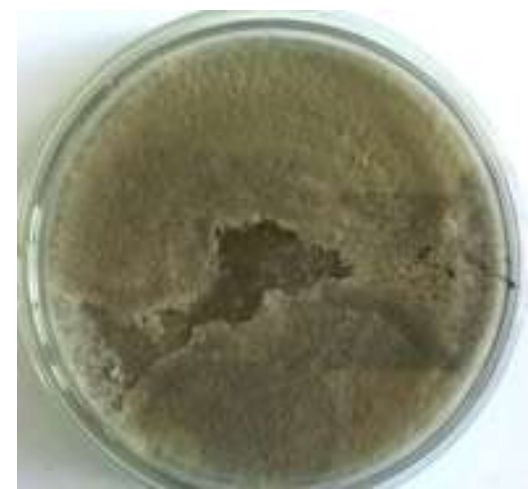

GMEF 9

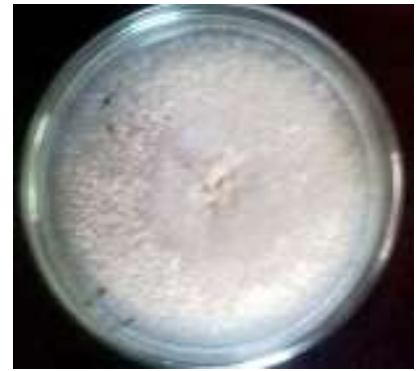

GMEF 2

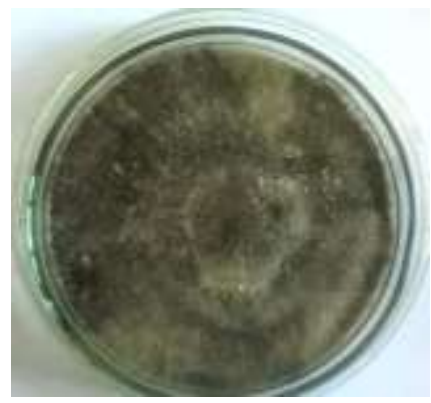

GMEF 6

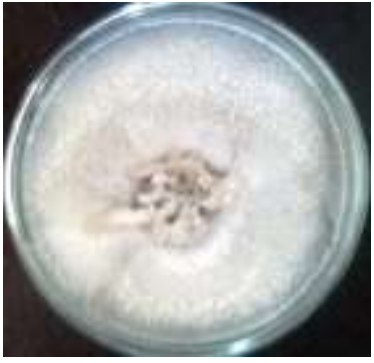

GMEF 3

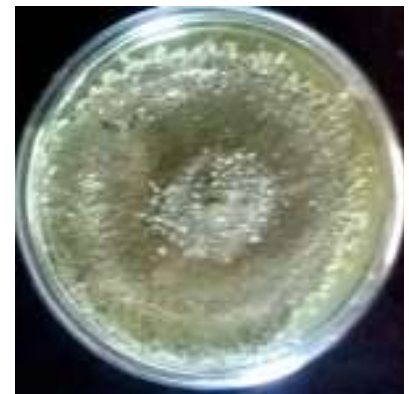

GMEF 7

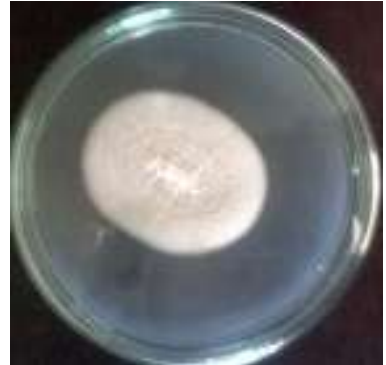

GMEF 4

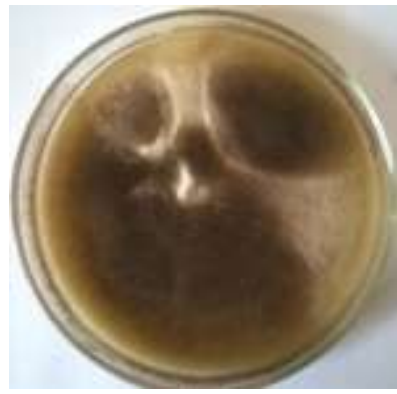

GMEF 8

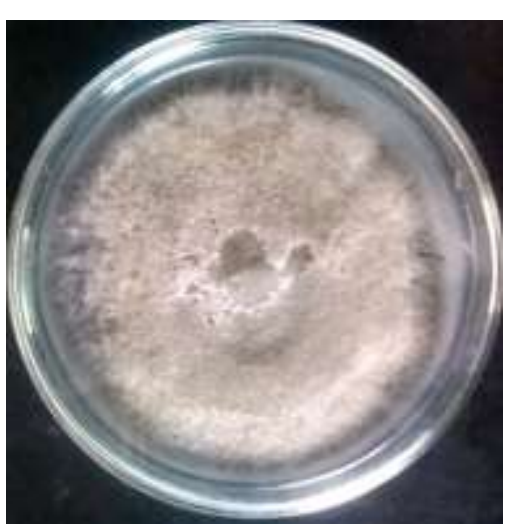

GMEF 10

Figure 1: Colony front views of the isolated fungal endophytes, GMEF1 to GMEF10 in Petri dishes from soybean. The period of culture at $28^{\circ} \mathrm{C}$ on PDA was in 7 to 10 days. A terreus (GMEF1), F. oxysporum 3 (GMEF2), F. oxysporum 4 (GMEF3), A. fumigates (GMEF4), Nigrospora sp. 1 GMEF , Nigrospora sp. 2 GMEF 6, T. harzianum 3 GMEF 7 , F. oxysporum 5 GMEF8, Dark sterile mycelia GMEF9, Dark sterile mycelia GMEF10

Table 1: Growth and CMC-ase activity of the isolated endophytic fungi (10 isolates) on agar media.

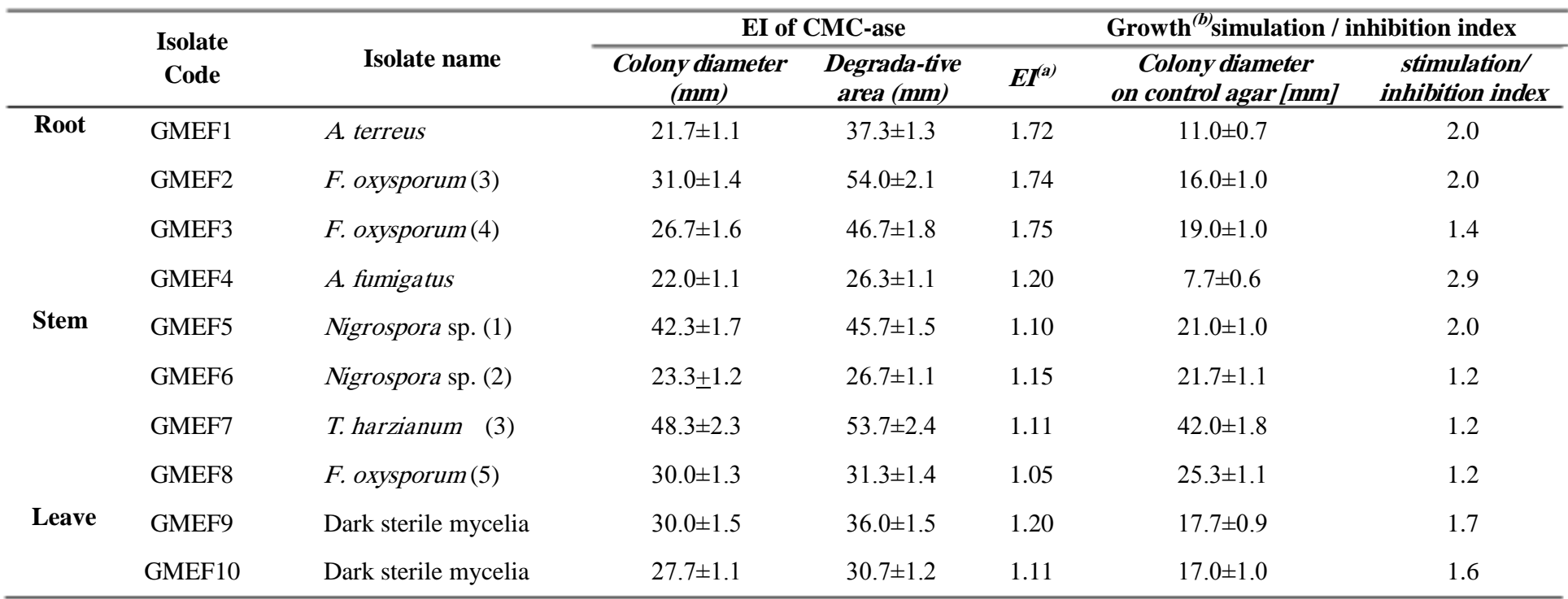

\section{(a) $E I=\phi \mathbf{h} / \phi \mathbf{c}$}

(b)Stimulation/inhibition index (CMC-colony/Control glucose-colony)

The index value $<1$, represented substrate inhibited fungal growth, while the index value $>1$, exhibited substrate rendered growth stimulation. The results of viable counts are expressed as mean $\pm \mathrm{SE}$ after $\log$ transformation. Mean is the value among treatments and SE is the standard error value for each treatment 
[a]CMC-ase(Congo red strain)

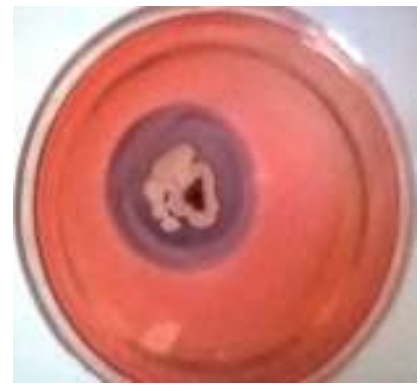

A terreus

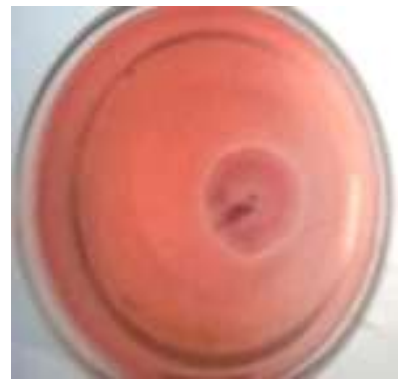

A. fumigatus

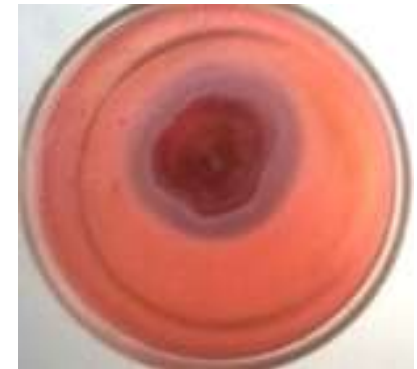

F. oxysporum (4)

[b]Xylanase(Congo red strain)

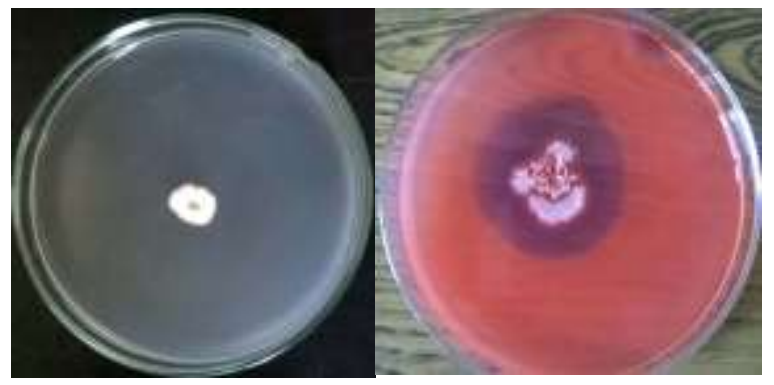

(Growth on Glucose)(Growth on xylan) Aspergillus terreus

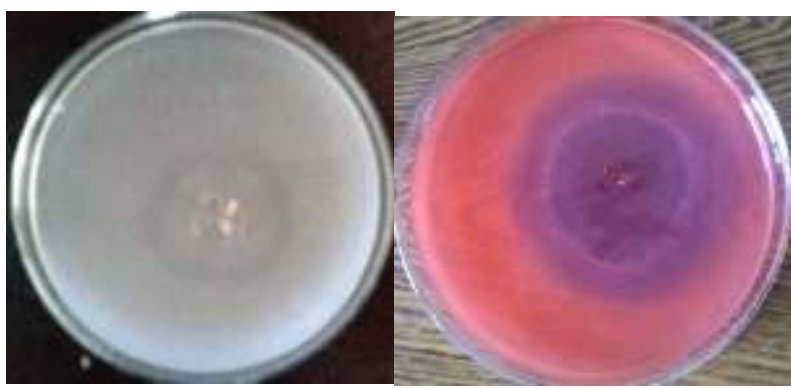

(without stain)(with Congo red stain) Fusarium oxysporum (3)

[c]

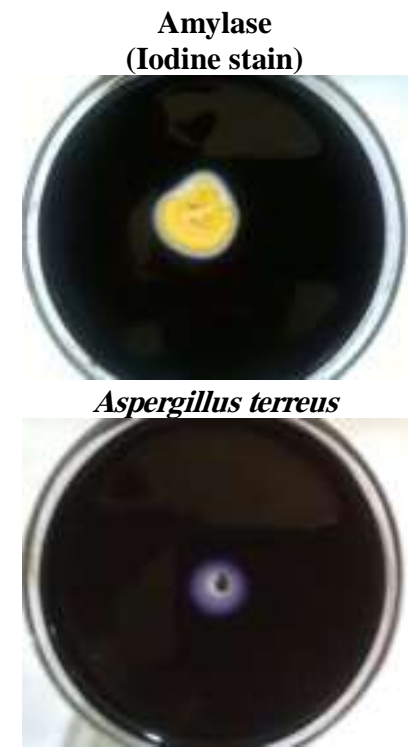

Nigrospora sp. (2)

\begin{tabular}{|c|c|c|c|c|c|}
\hline & \multirow[t]{2}{*}{ Isolate Code } & \multirow[t]{2}{*}{ Isolate name } & \multicolumn{3}{|c|}{$\begin{array}{c}\text { extracellular enzyme } \\
\text { production }\end{array}$} \\
\hline & & & CMC-ase & Xylanase & Amylase \\
\hline \multirow{10}{*}{ 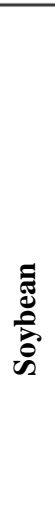 } & GMEF1 & A terreus & + & + & + \\
\hline & GMEF2 & F. oxysporum (3) & + & + & + \\
\hline & GMEF3 & F. oxysporum (4) & + & + & + \\
\hline & GMEF 4 & A. fumigatus & + & + & + \\
\hline & GMEF 5 & Nigrospora sp. (1) & + & + & + \\
\hline & GMEF 6 & Nigrospora sp. (2) & + & + & + \\
\hline & GMEF7 & T. harzianum (3) & + & + & + \\
\hline & GMEF 8 & F. oxysporum (5) & + & + & + \\
\hline & GMEF 9 & Dark sterile mycelia & + & + & + \\
\hline & GMEF 10 & Dark sterile mycelia & + & + & + \\
\hline
\end{tabular}

'+' indicates positive for enzyme test.

'-' indicates negative for enzyme test.

Figure 2: Enzyme production on agar plate by fungal endophytes isolated from soybean (Congo red, Iodine stains), zone of clearance on substrate amended agar plates.

[a] Clear zone indicating degradation of CMC by CMC-ase

[b] Clear zone indicating degradation of xylan by xylanase

[c] Clear zone indicating degradation of starch by Amylase; table of qualitatively extracellular enzyme 
Table 2: Growth and xylanase activity of the isolated endophytic fungi (10 isolates) on agar media.

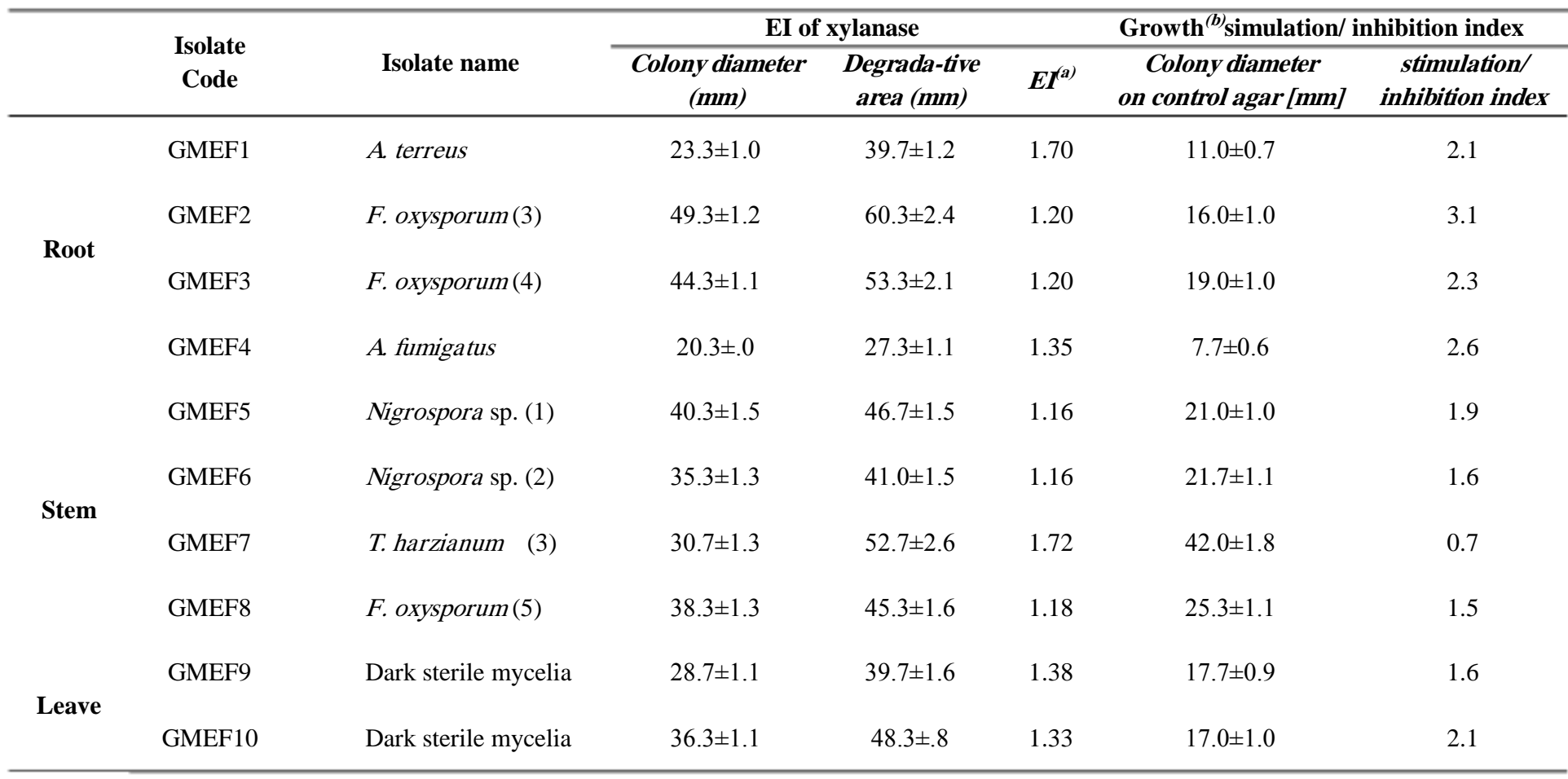

\section{(a) $E I=\phi \mathbf{h} / \phi c$}

\section{(b)Stimulation/inhibition index (Xylan-colony/Control glucose-colony)}

The index value <1, represented substrate inhibited fungal growth, while the index value $>1$, exhibited substrate rendered growth stimulation. The results of viable counts are expressed as mean $\pm \mathrm{SE}$ after $\log$ transformation. Mean is the value among treatments and SE is the standard error value for each treatment

Table 3: Growth and amylase activity of the isolated endophytic fungi (10 isolates) on agar media.

\begin{tabular}{|c|c|c|c|c|c|c|c|}
\hline & \multirow{2}{*}{$\begin{array}{c}\text { Isolate } \\
\text { Code }\end{array}$} & \multirow[b]{2}{*}{ Isolate name } & \multicolumn{3}{|c|}{ EI of amylase } & \multicolumn{2}{|c|}{ Growth $^{(b)}$ simulation / inhibition index } \\
\hline & & & $\begin{array}{c}\text { Colony diameter } \\
\text { (mm) }\end{array}$ & $\begin{array}{l}\text { Degrada-tive } \\
\text { area (mm) }\end{array}$ & $E I^{(a)}$ & $\begin{array}{c}\text { Colony diameter } \\
\text { on control agar [mm] }\end{array}$ & $\begin{array}{c}\text { stimulation/ } \\
\text { inhibition index }\end{array}$ \\
\hline \multirow{2}{*}{ Root } & GMEF2 & F. oxysporum (3) & $25.0 \pm 1.5$ & $25.0 \pm 1.1$ & 1.00 & $16.0 \pm 1.0$ & 1.6 \\
\hline & GMEF3 & F. oxysporum (4) & $10.0 \pm 9.0$ & $10.0 \pm 0.5$ & 1.00 & $19.0 \pm 1.0$ & 0.5 \\
\hline \multirow{3}{*}{ Stem } & GMEF5 & Nigrospora sp. (1) & $40.0 \pm 1.9$ & $12.0 \pm 0.8$ & 0.3 & $21.0 \pm 1.0$ & 1.9 \\
\hline & GMEF6 & Nigrospora sp. (2) & $5.0 \pm 0.6$ & $15.0 \pm 1.0$ & 3.00 & $21.7 \pm 1.1$ & 0.2 \\
\hline & GMEF7 & T. harzianum (3) & $50.0 \pm 2.3$ & $35.0 \pm 1.9$ & 0.7 & $42.0 \pm 1.8$ & 1.2 \\
\hline Leave & GMEF10 & Dark sterile mycelia & $10.0 \pm 1.1$ & $10.0 \pm 0.8$ & 1.00 & $17.0 \pm 1.0$ & 0.6 \\
\hline
\end{tabular}

\section{(a) $E I=\phi \mathbf{h} / \phi \mathbf{c}$}

\section{(b)Stimulation/inhibition index (Starch-colony/Control glucose-colony)}

The index value $<1$, represented substrate inhibited fungal growth, while the index value $>1$, exhibited substrate rendered growth stimulation. The results of viable counts are expressed as mean $\pm \mathrm{SE}$ after $\log$ transformation. Mean is the value among treatments and $\mathrm{SE}$ is the standard error value for each treatment 
xylan and starch degradation by CMC-ase (Figure 2A), xylanase (Figure 2B) and amylase (Figure 2C), respectively.

EI values in Tables 1, 2 and 3 clearly suggested that there was a variation in the production of different extracellular enzymes by the endophytic fungi isolated from soybean. EI ranged between $1.1-1.75,1.16-1.72$, and $0.3-3.0$ for the activity of CMC-ase, xylanase, and amylase, respectively. CMC-ase of endophyte GMEF1, GMEF2 and GMEF3 (EI 1.72, 1.74 , and 1.75 , respectively) showed significantly higher levels of activity when compared to others. Xylanase of endophyte GMEF1 and GMEF7 (EI 1.7 and 1.72, respectively) showed significantly higher levels of activity comparing with the other tested endophytes. EI of amylase for starch degradation on solid media showed no significantly difference between endophytes except for GMEF6 (EI 3.0) which displayed significantly level in its activity when compared with the others. The lowest amylase producers were GMEF5 and GMEF7 for starch degradation and their EI was lower than 1.0 (EI 0.3 and 0.7, respectively) which showed very low levels when compared with the other tested isolated fungi.

Derivative activity of endophytes for xylan on solid medium was performed with and without Congo red to calculated Enzymatic Index, and the two methods showed for some extent, the same pattern of results in data of degradative activity (Figure 2B).

\subsection{Growth simulation/inhibition}

Results of the endophytes' growth stimulation or inhibition on solid media in presence of different carbon sources compared with glucose as control varied according to isolates and type of carbon-source. Among the tested endophytes, all isolates were stimulated in colonies growth on CMC- and xylan-agar media except for Trichoderma harzianum (GMEF7), the inhibition was investigated $\mathrm{n}$ xylan-medium when compared to control amended with glucose only (Tables 1, 2). However, solid medium amended with starch showed inhibition to colony growth for 4 fungal endophytes ( $40 \%$ of the total tested endophytes) when compared with control of glucose as a sole carbon source, and the inhibition varied between isolates and ranged from 0.2-0.6 inhibition (Table 3). On the other hand, the greatest stimulation reached to 2.9 (A. fumigatus, GMEF4), 3.1 (Fusarium oxysporum 3, GMEF2) and 1.9 (Nigrospora sp. 1, GMEF5) in media amended with CMC, xylan and starch, respectively (Tables $\mathbf{1 , 2}, \mathbf{3}$ ).

Astonishingly, isolate of GMEF6 (Nigrospora sp. 2) on starch agar-medium showed the highest EI of amylase (3.0), it represented an inhibition of 0.2 in colony growth for the same substrate amended medium (Table 3). Moreover, GMEF2 (Fusarium oxysporum 3) represented stimulation in colony growth on xylan amended medium when compared with control of glucose; it gave EI value of xylanase as the lower level isolates (Table 2).

\section{Discussion}

Fungal endophytes are noticeably dispersed throughout the organs and tissues of plants and are associated with various plant structures, such as leaves, branches, stems, roots, shoots [19]. In this study, 10 fungal endophytes were isolated from soybean (Glycine max) and grouped into 5 different genera, including Aspergillus, Fusarium, Nigrospora, Trichoderma, and Dark sterile mycelia. Eight isolates of endophytes belonged to the phylum Ascomycota, which agreed with the statistical results showing that Basidiomycota endophytes were seldom found within plants [20]. We identified all the isolated endophytes based on morphology and conidial characteristics. Results supported the work of [21, 22] who also isolated the same taxa from soybean roots, stems and leaves.

In this study the most frequently isolated genus in soybean samples was Fusarium, in consistence with the reported results of endophytic fungi previously isolated from soybean [21-23]. Fungal endophytes were qualitatively analyzed for their ability to produce different variety of polysaccharide degrading enzymes, including CMC-ase, xylanase and amylase. These micro-organisms or their enzymes might have an array of biological industrial and environmental applications, like polymer hydrolysis, synthesis of chemicals, soil decontamination, biosynthesis of valuable compounds in plants or biological control of diseases, and decomposition of organic matter.

Earlier work employed testing on plates using the term clear zone or halo of degradative zone and calculation of Enzymatic Indices (EI) to determine amylase, cellulase, protease and lipase potential of twenty-six fungal endophytes isolated from Bacopa monnieri [24]. Furthermore, eighteen thermophilic bacteria were successfully screened in amylolytic activity at $0.002 \%$ starch agar plates, and the amylolytic indexes (ratio of clear zone diameter to colony diameter) were calculated and compared between isolates [25].

Enzymatic Index larger than 1.0 was indicative of excretion of enzymes with biotechnological potential [26]. The Enzymatic Indices above 1.0 clearly represent enzyme secretion outside the colony and those with values below 1.0 defined the colony growth higher than the enzymatic halo activity on agar [27]. This study showed that all of the tested fungal endophytes isolated from soybean represented the ability to produce the three evaluated enzymes on agar plates, and mostly EI values more than 1, proving their potential for industrial applications. In this study, all the endophytic fungi isolated (100\%) were able to degrade CMC and xylan by CMC-ase and xylanase enzymes, respectively. Some isolates have shown significant area of clear zone whereas some of them showed less area indicating different rate of enzyme production by different isolates. The rate of enzyme production by these endophytic fungi would be estimated after growing them in large batch culture for purification. According to starch degradation by amylase, all fungal endophytes were lower in their potential degradation compared with $\mathrm{CMC}$-ase and xylanase in degradation of $\mathrm{CMC}$ and xylan, respectively. This result is consistent with previously result of [24] who reported that cellulase was produced by all 
the mangrove endophytic fungi of Southwest Coast of India, whereas amylase activity was present only in a few of those.

Fungal endophytes of this study showed growth stimulation on CMC and xylan media, and were hyperactive in the presences of these substrates more than glucose. On the other hand, starch was investigated as lower preferable for these endophytes and in some isolates great inhibition occurred in the presence of starch as compare to glucose. This may be attributed to their genetic makeup and subsequent physiological conditions [28].The genetic machinery required to produce cell wall degrading enzymes such as cellulase, may already be present in endophytic fungi prior to the establishment of the symbiotic relationship with the host plant. From an evolutionary perspective, these endophytic fungal strains may have adapted to the respective metabolic machinery of the host tissues to produce biomolecules not only important for their own biology, but also for requirements of the host plant. The relationship between the endophytes and plants is symbiotic, where endophytes produce natural products for protecting the plant host against the pests and pathogens.

\section{Conclusion}

The current study obviously revealed the significant extracellular enzymes production of the fungal endophytes isolated from soybean. All isolated endophytes (100 \%) exhibited CMC-ase, xylanase and amylase activities. This finding, accordingly approve the efficient use of fungal endophytes as a source for hydrolytic enzymes and could explore their industrial and food-related applications. Further research on the isolation and characterization of those enzymes will thus be motivationally considered.

Financial Disclosure Statement: "The authors received no specific funding for this work."

Conflict of Interest: The authors declare that they have no conflict of interest.

Acknowledgments: We thank Dr. Soad Nasr (Botany and Microbiology Department, Faculty of Science, Minia University, Egypt) for the identification of the endophytic fungal isolates.

\section{References}

[1] Hardoim P, Van Overbeek L, Berg G, Pirttilä A, Compant S, Campisano A, et al. The Hidden World Within Plants: Ecological and evolutionary considerations for defining functioning of microbial endophytes. Microbiol Mol Biol Rev. 2015;79:293-320.

[2] Rodriguez RJ, White JF, Jr., Arnold AE, Redman RS. Fungal endophytes: diversity and functional roles. New Phytol. 2009;182(2):314-30.

[3] Kusari S, Pandey SP, Spiteller M. Untapped mutualistic paradigms linking host plant and endophytic fungal production of similar bioactive secondary metabolites. Phytochemistry. 2013:91:81-7.

[4] Zhao J, Shan T, Mou Y, Zhou L. Plant-derived bioactive compounds produced by endophytic fungi. Mini Rev Med Chem. 2011;11(2):159-68.

[5] Tong WY, Darah I, Latiffah Z. Antimicrobial activities of endophytic fungal isolates from medicinal herb Orthosiphon stamineus Benth J Med Plants Res. 2011;5(5):831-6.
[6] Firáková S, Šturdíková M, Múčková M. Bioactive secondary metabolites produced by microorganisms associated with plants. Biologia. 2007;62(3):251

[7.] de Veras B, dos Santos Y, Diniz K, Carelli G, dos Santos E. Screening of protease, cellulase, amylase and xylanase from the salt-tolerant and thermostable marine Bacillus subtilis strain SR60 [version 1; peer review: 1 approved with reservations]. F1000Research. 2018;7(1704).

[8] Waqas MK, Akhtar N, Mustafa R, Jamshaid M, Khan HM, Murtaza G. Dermatological and cosmeceutical benefits of Glycine max (soybean) and its active components. Acta Pol Pharm. 2015;72(1):3-11.

[9] Asif M, Acharya M. Phytochemicals and nutritional health benefits of soy plant. Int J Nutr Pharmacol Neurol Dis. 2013;3(1):64-9.

[10] Strobel G, Daisy B. Bioprospecting for microbial endophytes and their natural products. Microbiol Mol Biol Rev. 2003 67(4):491-502.

[11] Andrews S, Pitt JI. Selective medium for isolation of Fusarium species and dematiaceous hyphomycetes from cereals. Appl Environ Microbiol. 1986;51(6):1235-8

[12] Barnett HL, Hunter BB. Illustrated genera of imperfect fungi. Minnesota.: Burgess Publishing Company.; 1972.

[13] Hankin L, Anagnostakis SL. The Use of Solid Media for Detection of Enzyme Production by Fungi. Mycologia. 1975;67( 3 ):597-607

[14] El-Katatny MH. Enzyme production and nitrogen fixation by free, immobilized and coimmobilized inoculants of Trichoderma harzianum and Azospirillum brasilense and their possible role in growth promotion of tomato. Food Technol Biotechnol. 2010;8 (2):161-74.

[15] Pragya R., Yasmin A., J. A. An insight into agricultural properties of actinomycetes. Int J Res Bio Sci. 2012;1(1):7-12.

[16] Lin J-E, Chang DCN, Shen G-J, Wang HY. Correlations among several screening methods used for identifying wood-decay fungi that can degrade toxic chemicals. Biotechnol Tech. 1991;5(4):275-80.

[17] Herculano PN, Lima DMM, Fernandes MJS, Neves RP, Souza-Motta CM Porto ALF. Isolation of Cellulolytic Fungi from Waste of Castor (Ricinus communis L.). Curr Microbiol. 2011;62(5):1416-22.

[18] Lubeck M, Lubeck PS. Isolation and Screening of Cellulolytic Filamentous Fungi. Methods in molecular biology (Clifton, NJ). 2018;1796:37-45.

[19] Porras-Alfaro A, Bayman P. Hidden fungi, emergent properties: endophytes and microbiomes. Annual review of phytopathology. 2011;49:291315.

[20] Crozier J, Thomas SE, Aime MC, Evans HC, Holmes KA. Molecular characterization of fungal endophytic morphospecies isolated from stems and pods of Theobroma cacao. Plant Pathol J. 2006;55(6):783-91.

[21] Impullitti AE, Malvick DK. Fungal endophyte diversity in soybean. J Appl Microbiol. 2013;114(5):1500-6.

[22] Russo ML, Pelizza SA, Cabello MN, Stenglein SA, Vianna MF, Scorsetti AC. Endophytic fungi from selected varieties of soybean (Glycine max L. Merr.) and corn (Zea mays L.) grown in an agricultural area of Argentina. Revista Argentina de microbiologia. 2016;48(2):154-60.

[23] Pimentel IC, Glienke-Blanco C, Gabardo J, Stuart RM, Azevedo JL. Identification and colonization of endophytic fungi from soybean (Glycine max (L.) Merril) under different environmental conditions. Braz arch biol technol 2006;49:705-11.

[24] Katoch M, Salgotra A, Singh G. Endophytic fungi found in association with Bacopa monnieri as potential producers of industrial enzymes and antimicrobial bioactive compounds. Braz arch biol technol 2014;57:714-22.

[25] Gazali FM, Suwastika IN. Thermostable $\alpha$-amylase activity from Thermophilic Bacteria Isolated from Bora Hot Spring, Central Sulawesi. J Appl Phys Conference Series. 2018;979:012001.

[26] Carrim AJI, Barbosa EC, Vieira JDG. Enzymatic activity of endophytic bacterial isolates of Jacaranda decurrens Cham. (Carobinha-do-campo) Brazilian Archives of Biology and Technology. 2006;49:353-9.

[27] Colonia BSO, Chagas Junior AF. Screening and detection of extracellular cellulases (endo- and exo-glucanases) secreted by filamentous fungi isolated from soils using rapid tests with chromogenic dyes. . African Journal of Biotechnology. 2014;13(52):4694-701.

[28] Parekh S, Vinci VA, Strobel RJ. Improvement of microbial strains and fermentation processes. Applied microbiology and biotechnology. 2000;54(3):287-301. 